\title{
A New Record of Collix stellata (Lepidoptera: Geometridae) from Korea
}

\author{
Sei-Woong Choi*, Sang-Hyun $\mathrm{Na}$ \\ Department of Environmental Education, Mokpo National University, Muan 534-729, Korea
}

\begin{abstract}
We report a larentiine species, Collix stellata Warren, for the first time from Korea. Two males and one female were collected from Jeju-do Island, South Korea. Collix stellata is similar to Collix ghosa Walker in external appearances, but can be distinguished by the relatively larger discal dot on forewing and the relatively slender valva with distally projected margin of male genitalia. Diagnosis and description of the species are given with the figures of the genitalia.
\end{abstract}

Keywords: Lepidoptera, Geometridae, Collix stellata, taxonomy, Korea

\section{INTRODUCTION}

The genus Collix Guenée is an Old World tropical taxon of Geometridae, ranging in geographical distribution from Sri Lanka to Fiji (Holloway, 1997). The genus was designated with Collix hypospilata Guenée as the type species and now comprises 33 species worldwide (Scoble, 1999). Moths of Collix are characterized by a black and large discal dot and numerous fasciae that are parallel to wing margins on the forewing, a discal dot and dark blackish postmedial and submarginal fasciae on the underside of the forewing, central apodeme on the sixth male sternite, pairs of coremata on male abdomen, slender uncus and simple valva of male genitalia and narrow ductus bursae and a longitudinal band of signa on the corpus bursae of female genitalia (Holloway, 1997).

The present report describes a larentiine species, Collix stellata Warren, for the first time in Korea. Three specimens were collected at the southern slope of Mt. Halla-san, Jejudo. Examination of adults including the male and female genitalia refers to Scoble (1992). Abbreviations are as follows: TL, type locality; MNU, Mokpo National University, Jeonnam; JJ, Province Jeju-do.

\section{SYSTEMATIC ACCOUNTS}

Order Lepidoptera Linnaeus, 1758

Family Geometridae Stephens, 1829

Subfamily Larentiinae Duponchel, 1845

Genus Collix Guenée, [1858]

${ }^{1 *}$ Collix stellata Warren (Figs. 1, 2)

Collix stellata Warren, 1894: 679 (TL: India, Khasia Hills).

Collix griseipalpis Wileman, 1916: 34 (TL: Taiwan, Kanshirei).

Collix griseipalpis relocate Prout, 1932: 105 (TL: India, Khasia Hills).

Materials examined. Korea: JJ, 1 우, Seoguipo-si, Namwoneup, Silye-ri, Mt. Halla-san, $33^{\circ} 19^{\prime} 56.7^{\prime \prime} \mathrm{N}, 126^{\circ} 36^{\prime} 25.7^{\prime \prime} \mathrm{E}$, 499 m, 2 Oct 2008 (MNU); $2 \sigma^{\top}$, same locality, 8 Sep 2010 (MNU).

Diagnosis. This species is distinguished by the filiform antennae, long projected labial palpi, light grayish fore- and hindwings with a large black discal dot and dark grayish medial line and termen and a large black discal dot and blackish transverse medial and subterminal lines on the underside of the fore- and hindwings. The male genitalia can be distinguished by the slender uncus, setose anal tube at the apex, short digitate labides, short calcar with apical setae and simple membranous valva with projected distal margin. The female

\footnotetext{
(C) This is an Open Access article distributed under the terms of the Creative Commons Attribution Non-Commercial License (http://creativecommons.org/ licenses/by-nc/3.0/) which permits unrestricted non-commercial use, distribution,
} and reproduction in any medium, provided the original work is properly cited.

*To whom correspondence should be addressed

E-mail: choisw@mokpo.ac.kr

Korean name: ${ }^{1 *}$ 남방큰점물결자나방 (신칭) 


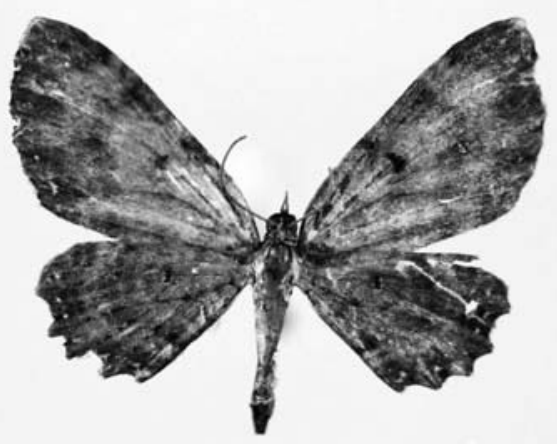

A

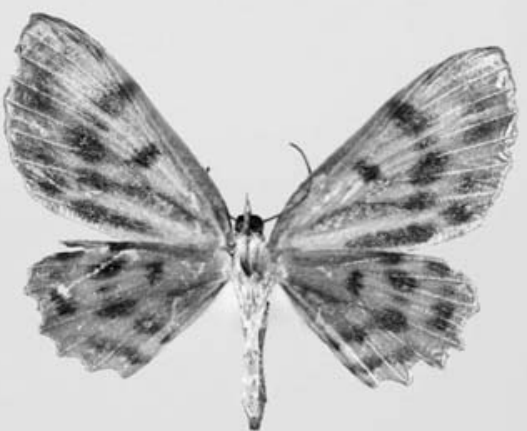

B

Fig. 1. Adult of Collix stellata Warren from Korea. A, Upper side; B, Underside.
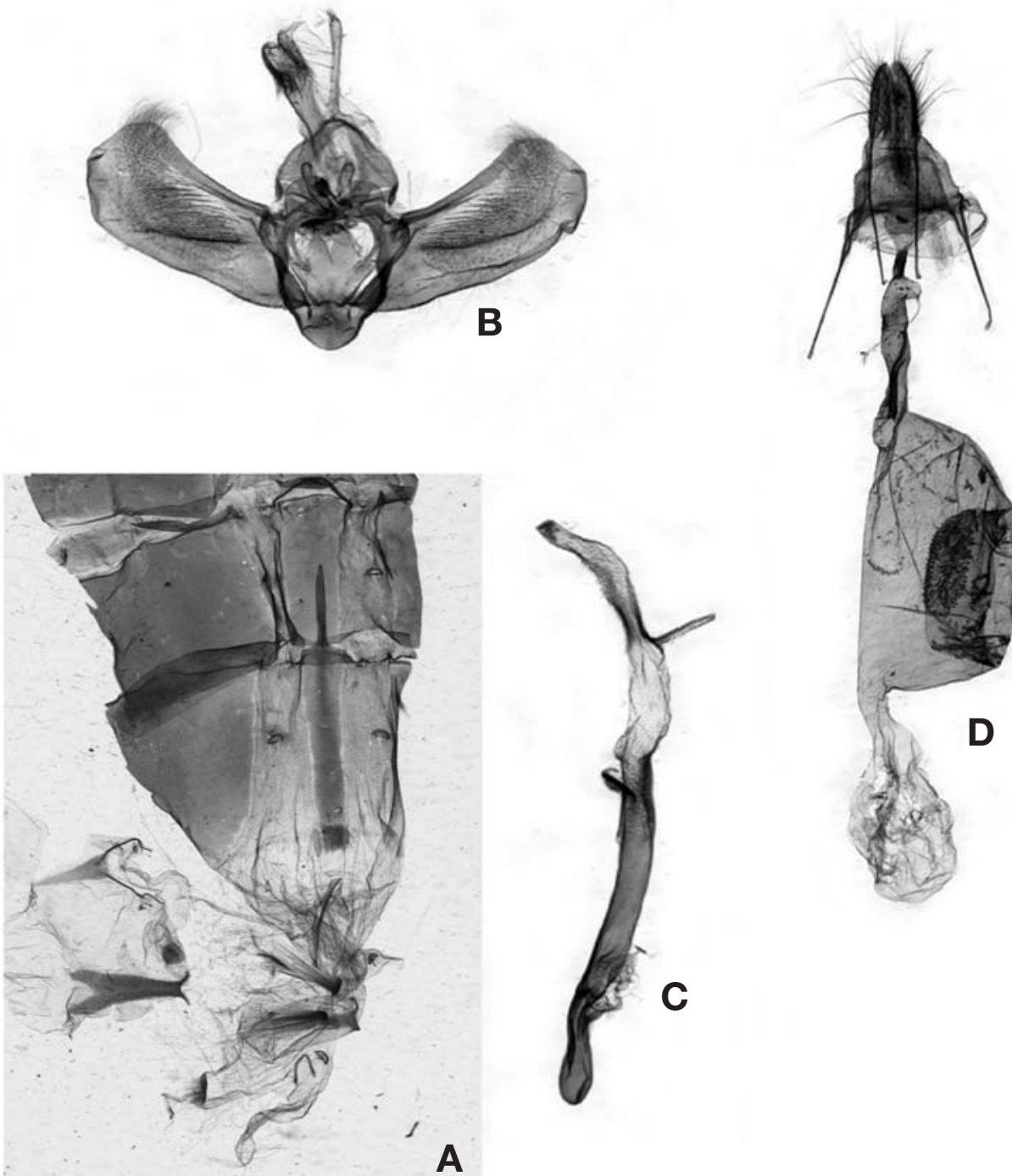

A

Fig. 2. Male and female genitalia of Collix stellata Warren from Korea. A, Male abdomen; B, Male genital capsule; C, Aedeagus; D, Female genitalia. 
genitalia can be distinguished by the long anterior and posterior apophyses, V-shaped antrum, narrow and elongated colliculum, relatively long ductus bursae with a long sclerotized spine, large soft-hat shaped corpus bursae with a row of signa and an ovate appendix bursae. This species is similar to Collix ghosa Walker in external appearances, but can be distinguished by the relatively larger discal dot on forewing and the relatively slender valva with distally projected margin of male genitalia.

Description. Wingspan 26-28 mm. Antennae filiform; frons broad, trapezoidal, mixed with dark ochreous scales; labial palpi very long, almost twice the eye diameter, projected forward. Body and legs covered with whitish scales. Forewing ground color light grayish, costa thinly covered with dark brown scales; central fascia dark brownish, costally projected outward, with a large blackish discal dot, two areoles; termen dark brownish with an undulating whitish line. Underside of forewing light grayish with a large black discal dot; thick blackish medial line costally projected, termen blackish with a dark blackish subterminal line. Hindwing ground color light grayish; blackish transverse lines present in basal, medial and subterminal areas; a small discal dot present but smaller than on the forewing; termen with undulating margin. Underside of hindwing with a large discal dot; thick, blackish transverse lines at median and subtermen.

Male abdomen and genitalia (Fig. 2A-C). Sixth sternite with a long slender apodeme; eighth sternite with a pair of coremata. Uncus slender, apex slightly expanded. Anal tube narrow and elongated, apex densely covered with fine setae. Valve long and relatively narrow, with almost parallel dorsal and ventral margins, distal margin projected outward; costa thin, slender, lightly sclerotized. Vinculum V-shaped, tapered anteriorly. Papillae on the anterior arms of labides short, digitate; posterior arms of labides large, armor-shaped. Calcar short, setose at apex. Aedeagus slim, a patch of minute spines at apex. Vesica long, tubular with very minute cornuti near apex.

Female genitalia (Fig. 2D). Papillae anales elongated, slightly tapered to apices, covered with elongated and mediumsized setae. Anterior and posterior apophyses long and almost the same length. Antrum V-shaped and membranous. Colliculum collar-like, narrow and elongated. Ductus bursae long, narrow with a long spine anteriorly. Corpus bursa relatively large, soft-hat shaped, membranous, with membranous lateral hollow and row of dense setae. Appendix bursae ovate, membranous.

Distribution. Korea, Japan, Taiwan, and N. India.

Biology. Flying period of moths is from early September to October in Korea and Taiwan (Prout, 1914), while June in Japan (Suzuki et al., 2003). The food plants of larvae are Rapaneae nerifolia (S. et. Z.) Mez (Myrsinaeceae) and Lacymachia clethroides Duby (Primulaceae) in Japan (Suzuki et al., 2003).

\section{ACKNOWLEDGEMENTS}

We would like to thank Mr. Jeong-Seop An for aiding in collecting moths. This study was supported by the project on the survey and excavation of Korean indigenous species of the National Institute of Biological Resources (NIBR) under the Ministry of Environment, Korea.

\section{REFERENCES}

Holloway JD, 1997. The moths of Borneo: family Geometridae, subfamilies Sterrhinae and Larentiinae. Malayan Nature Journal, 51:1-242.

Prout LB, 1914. H. Sauter's Formosa-Ausbeute. Geometridae (Lep.). Entomologische Mittelungen, 3:236-249.

Prout LB, 1932. New exotic Geometridae. Novitates Zoologicae, 38:103-126.

Scoble MJ, 1992. The Lepidoptera: form, function and diversity. Oxford University Press, Oxford, pp. 1-404.

Scoble MJ, 1999. Geometrid moths of the world: a catalogue (Lepidoptera, Geometridae). Vol. 1. CSIRO Publishing and Apollo Books, Stenstrup, pp. 1-482.

Suzuki T, Jinbo U, Sakamoto Y, 2003. An identification guide of Japanese moths compiled by everyone. Accessed 11 Apr 2011, <http://www.jpmoth.org/> (in Japanese).

Warren W, 1894. New species and genera of Indian Geometridae. Novitates Zoologicae, 1:678-682.

Wileman AE, 1916. New species of Geometridae from Formosa. The Entomologist, 49:34-37.

Received May 2, 2011 Accepted June 13, 2011 